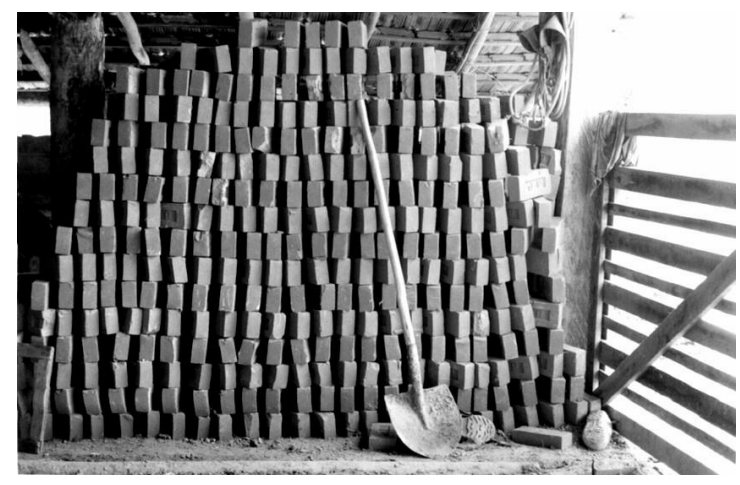

\title{
Formação dos conceitos científicos e práticas pedagógicas*
}

Cleide Nébias ${ }^{1}$

Todos nós organizamos as informações que internalizamos para garantirmos nossa sobrevivência e nossa permanência em um grupo social. Segundo Smith (1991), para compartilharmos da cultura de um grupo social devemos compartilhar de uma mesma base categórica que organiza nossa experiência; isso significa desenvolvermos uma "teoria de mundo" que dá sentido ao que somos expostos e nos impede de enfrentarmos o novo com perplexidade. Em outras palavras, vemos o mundo e tentamos compreender seu funcionamento, com "óculos conceituais". Inicialmente com conceitos cotidianos, alternativos, espontâneos, ou pré-conceitos, que vão dando lugar aos conceitos científicos.

Pelo papel que os conceitos desempenham, sua aprendizagem tem sido objeto de muitas investigações, principalmente quando se pensa na instrução formal e no papel da escola de facilitadora na construção do conhecimento científico por parte de seus alunos.

Vygotsky foi um dos estudiosos desse tema, desenvolvendo alguns estudos experimentais para observar a dinâmica do processo de

formação de conceitos. Mais de trezentas pessoas foram estudadas crianças, adolescentes e adultos. As principais conclusões a que chegou foram:

\footnotetext{
* Trabalho apresentado em mesa-redonda no IX Endipe - Encontro Nacional de Didática e Prática de Ensino, Águas de Lindóia, SP, 1998.

${ }^{1}$ Professora do Programa de Pós-Graduação em Psicologia da Universidade São Marcos e professora visitante do Programa de PósGrduação em Educação da Universidade Estadual Paulista - Unesp - campus de Marília.
} 
. a percepção e a linguagem são indispensáveis à formação de conceitos;

- a percepção das diferenças ocorre mais cedo do que a das semelhanças porque esta exige uma estrutura de generalização e de conceitualização mais avançada;

- o desenvolvimento dos processos que resultam na formação de conceitos começa na infância, mas as funções intelectuais que formam a base psicológica do processo de formação de conceitos amadurece e se desenvolve somente na adolescência;

- a formação de conceitos é o resultado de uma atividade complexa, em que todas as funções intelectuais básicas (atenção deliberada, memória lógica, abstração, capacidade para comparar e diferenciar) tomam parte;

- os conceitos novos e mais elevados transformam o significado dos conceitos inferiores (Vygotsky, 1991).

As pesquisas do autor demonstraram que

há três fases básicas na trajetória da formação de conceitos:

1 Agregação desorganizada - amontoados vagos de objetos desiguais, fatores perceptuais são irrelevantes; predomínio do sincretismo.

Vygotsky chama a atenção para o fato de que uma criança de três anos e um adulto podem se entender porque partilham de um mesmo contexto $e$ utilizam um grande número de palavras com o mesmo significado, mas baseadas em operações psicológicas diferentes (características concretas/ significações abstratas); isso significa que o conceito no sentido real não está desenvolvido.

"(...)Vygotsky conclui que o conceito em si e para os outros existe antes de existir para a própria criança, ou seja, a criança pode aplicar palavras corretamente antes de tomar consciência do conceito real" (Der Veer \& Valsiner, 1996, p.291). Essa afirmação, mais uma vez, explicita a concepção de Vygotsky de que todo conhecimento é primeiramente interpsicológico para depois tornar-se intrapsicológico.

2 Pensamento por complexos - os objetos associam-se não apenas devido às impressões subjetivas da criança, mas também devido às relações concretas e factuais que de fato existem entre esses objetos, podendo, entretanto, mudar uma ou mais vezes durante o processo de ordenação. Essas características selecionadas podem parecer irrelevantes para os adultos (Der Veer \& Valsiner, 1996).

Num estágio avançado dessa fase, Vygotsky identifica a combinação de objetos em grupos com base em alguma característica que os torna diferentes e, ao mesmo tempo, complementares entre si, que se assemelham a coleções. $\mathrm{Na}$ passagem para os conceitos propriamente ditos, há um último tipo de complexos, o pseudoconceito, estágio no qual a criança generaliza fenotipicamente, mas psicologicamente seu conceito é muito diferente do conceito propriamente dito do adulto.

O pensamento por complexos é característico dos povos primitivos,

para os quais uma palavra não é portadora de um conceito, mas do "nome de família" para grupos de objetos concretos, 
associados factualmente; é também "característico dos esquizofrênicos, que regridem do pensamento conceitual para um nivel mais primitivo de intelecção, rico em imagens e símbolos" (Vygotsky,1991, p.62).

$3 \mathrm{Na}$ terceira fase da formação de conceitos, o grau de abstração deve possibilitar a simultaneidade da generalização (unir) e da diferenciação (separar). Essa fase exige uma tomada de consciência da própria atividade mental porque implica numa relação especial com o objeto, internalizando o que é essencial do conceito e na compreensão de que ele faz parte de um sistema. Inicialmente formam-se os conceitos potenciais, baseados no isolamento de certos atributos comuns, e em seguida os verdadeiros conceitos. Essa abstração vai ocorrer na adolescência. "No entanto, mesmo depois de ter aprendido a produzir conceitos, o adolescente não abandona as formas mais elementares; elas continuam a operar ainda por muito tempo, sendo na verdade predominantes em muitas áreas do seu pensamento. A adolescência é menos um período de consumação do que de crise e transição" (Vygotsky,1991, p.68).

Por seus experimentos, Vygotsky conclui que a capacidade do adolescente de formar conceitos antecede em muito sua capacidade de defini-los. Contudo, se considerarmos as situações escolares, muitas vezes o aluno é capaz de definir um objeto, quando sabemos que ainda não formou o conceito.

Outro aspecto bastante relevante sobre formação de conceitos, tratado por Vygotsky (1991), diz respeito aos processos cotidianos, à experiência pessoal da criança e à instrução formal, à aprendizagem em sala de aula, que, em seu entender, desenvolvem dois tipos de conceitos que se relacionam e se influenciam constantemente. Nesse aspecto, contesta Piaget, por ter sobre esse assunto um ponto fraco na sua teoria, uma vez que para Piaget os conceitos "espontâneos", que constituem as idéias da criança acerca da realidade, são independentes dos conceitos "nãoespontâneos", decisivamente influenciados pelos adultos e que vão gradativamente substituindo os primeiros. Vygotsky acredita que os conceitos espontâneos e os conceitos não-espontâneos não estão em conflito; fazem parte de um mesmo processo, ainda que se formem e se desenvolvam sob condições externas e internas diferentes e motivados por problemas diferentes.

Para Vygotsky (1991), esses conceitos cotidianos e científicos envolvem experiências $e$ atitudes diferentes por parte das crianças e se desenvolvem por caminhos diferentes; "a ausência de um sistema é a diferença psicológica principal que distingue os conceitos espontâneos dos conceitos científicos" (p.99). Um conceito espontâneo é definido por seus aspectos fenotípicos, sem uma organização consistente e sistemática, enquanto o conceito científico é sempre mediado por outros conceitos.

Os conceitos científicos foram objeto de vários estudos porque, com seu sistema hierárquico de inter-relações - um conceito supra-ordenado e uma série de conceitos subordinados -, "parecem" constituir, para Vygotsky, o meio no qual a consciência reflexiva se desenvolve. Desde o início, eles contêm relações de generalidade, por suas características essenciais. Mereceram atenção especial, também, porque a aprendizagem escolar exerce 
papel importante em sua aquisição. Segundo ele, nas experiências cotidianas, a criança centra-se nos objetos e não tem consciência de seus conceitos (por ex. usa corretamente a conjunção porque, mas não é capaz de fazê-lo numa situação experimental), ao passo que nos conceitos aprendidos na escola, em colaboração com o adulto, consegue resolver melhor problemas que envolvem o uso consciente do conceito. No entanto, seus estudos confirmaram a hipótese de que os conceitos espontâneos e os conceitos científicos, inicialmente afastados porque se desenvolvem em direções contrárias, terminam por se encontrar.

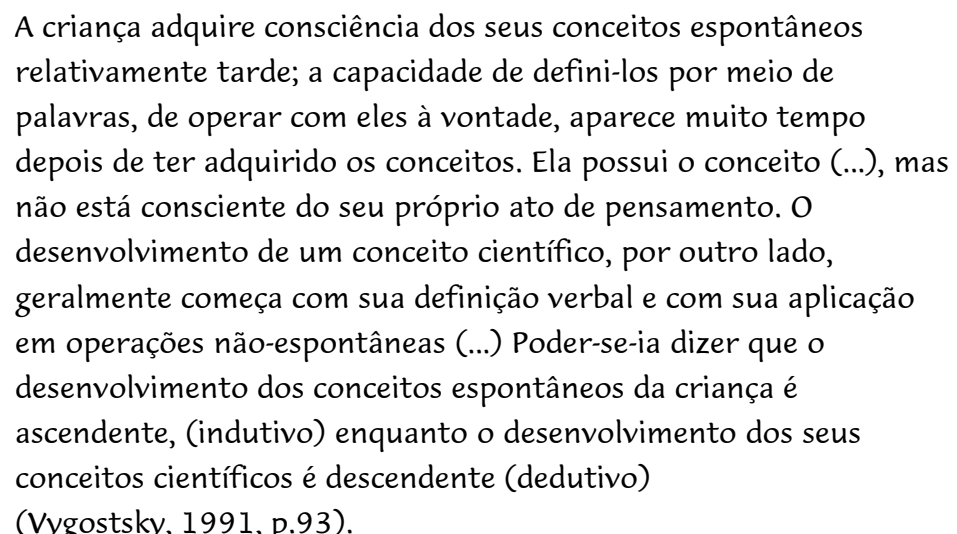

Contudo, Vygotsky afirma que é necessário que o conceito espontâneo tenha alcançado um certo nível para que o conceito científico correspondente seja internalizado (por ex. conceitos históricos dependem da utilização de passado nos acontecimentos cotidianos). Eles dependem e se constróem a partir dos conceitos cotidianos.

A comparação que Vygotsky estabelece entre a aquisição de conceitos científicos e aprendizagem de uma língua estrangeira é bastante elucidativa; na língua materna, aprendemos a partir da nomeação direta dos objetos enquanto, para uma língua estrangeira, a mediação da língua materna substitui o objeto.

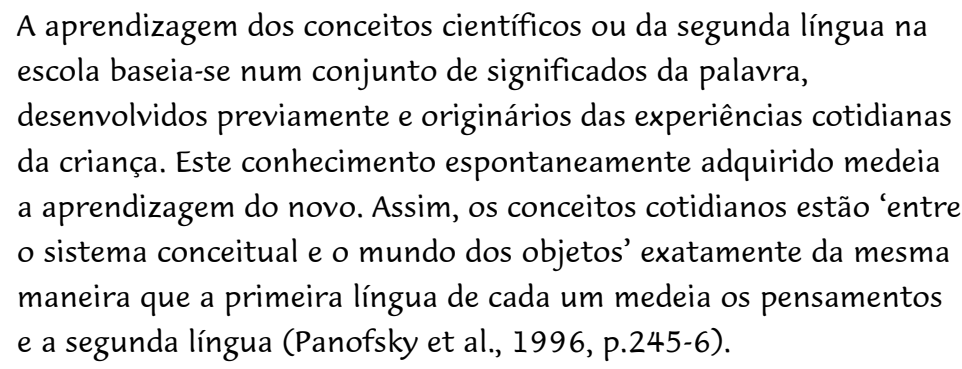

Vários estudos vêm sendo realizados após os trabalhos experimentais de Vygotsky. Alguns também experimentais, mas outros etnográficos e, principalmente, na área biológica, confirmam e ampliam alguns resultados obtidos por ele e refutam outros (como a inexistência de conflitos entre os 
conceitos espontâneos e científicos).

Panofsky et al. (1996), em seu trabalho sobre conceitos científicos, mencionam uma pesquisa evolutiva desenvolvida por Katherine Nelson e colaboradores e emprestam deles o termo "scripts" como representações de eventos generalizados que se desenvolvem espontaneamente a partir das primeiras experiências cotidianas da criança, que vão sendo generalizadas $e$ contextualizadas por seus aspectos perceptivos e funcionais, numa seqüência de eventos que se agrupam, formando o roteiro de eventos significativos que, com o tempo, vão sofrendo um processo de análise ou parcelamento, deles derivando os conceitos. Segundo Panofsky et al., a pesquisa de Nelson, baseada na observação da cognição cotidiana, avança sobre a pesquisa experimental de

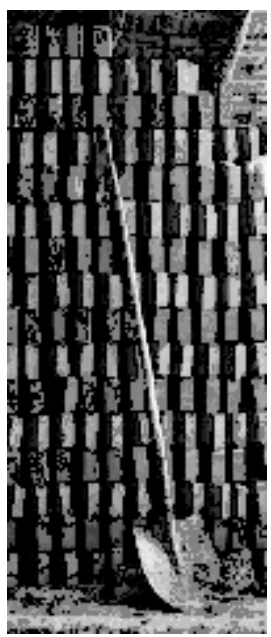
Vygotsky, na medida em que para ele os conceitos espontâneos não constituem um sistema, ao passo que para Nelson "as crianças constróem regularidades, conexões e sistematicidades na seqüência das atividades diárias, muito embora tais construções não sejam tão sofisticadas como serão posteriormente no domínio dos conceitos científicos" (Panofsky et al., 1996, p. 248).

Nos estudos de Panofsky et al., uma criança agrupa pássaro e borboleta porque os dois voam (agrupamento por script) e, alternativamente, pássaro $e$ avestruz porque, num sentido taxionômico, eles são pássaros. Segundo essas autoras, a combinação de categorias de script e taxionomia representa uma fase de transição de conceitos ligados à experiência dos conceitos sistematicamente organizados.

Shiff (apud Der Verr \& Valsiner, 1996) realizou suas investigações com conceitos ensinados pelo movimento comunista na União Soviética, como exemplo de conceitos científicos, seguindo o procedimento de Piaget com frases interrompidas para serem completadas (por ex: para conceitos cotidianos: A menina lê mal, embora... e O piloto caiu com o seu avião porque... e para os conceitos científicos:. A polícia atirou nos revolucionários porque... e Ainda há trabalhadores que acreditam em Deus, embora ...). Os sujeitos, crianças de sete a doze anos, responderam de forma mais correta as frases de conceitos científicos, embora esteriotipadas.

Shiff mostrou-se inclinada a interpretar esse fenômeno de forma positiva. Em sua opinião, a necessidade de repetir o material científico na classe, a necessidade de responder a perguntas sobre esse material e de explicar essas respostas levavam a criança à tomada de consciência dos conceitos científicos. Era a falta dessa tomada de consciência que levava as crianças a darem respostas tautológicas no teste cotidiano (...) (Der Verr \& Valsiner, 1996, p.298). 
Antes do ingresso na escola, a criança já construiu um conjunto de conhecimento informal, produto do desenvolvimento ontogenético a partir de suas experiências e que constitui o seu sistema de crenças sobre o mundo, a influenciar profundamente a obtenção do conhecimento formal, que se dará de forma planejada pela aprendizagem escolar.

Segundo Pines \& West (1984), as situações de aprendizagem escolar podem ser de vários tipos:

1 Situação de conflito, quando os conceitos espontâneos e científicos se confrontam; isso implica no abandono de idéias que prevaleceram por um período de tempo, o que pode ser difícil para o sujeito, mesmo quando isso se dá com adultos. Para Duarte (1996), realizando várias investigações na área de Biologia, um grande número de estudantes, de diferentes graus de ensino, mostram uma "persistência desconcertante" das idéias alternativas, quando essas diferem das idéias científicas veiculadas pela escola, funcionando como verdadeiros obstáculos epistemológicos na aprendizagem do conhecimento científico (p.22).

2 Situação congruente, quando os conceitos se integram e não há necessidade de abandonar os conhecimentos espontâneos, que se integram em um todo maior. Cita-se um exemplo dado por Ausubel da concepção da criança quanto ao corpo humano ser um saco cheio de sangue. De fato, o corpo sangra quase sempre e em quase todo o lugar espetado, devido à extensão da rede de capilares.

3 Situação formal-simbólica/zero-espontânea, quando existe pouco conhecimento espontâneo para interagir com o conhecimento formal apresentado na escola. Por exemplo, algumas reações de química orgânica.

4 Situação espontânea/não instruída, quando o conhecimento espontâneo é extenso, rico e suficiente e não há conhecimento escolar correspondente a ser apresentado. É o caso das crenças e das metáforas culturais que têm poderosa influência na aquisição conceitual.

Considerando, então, que o aluno traz uma riqueza de conhecimentos sobre o mundo e seu funcionamento, que na maioria das vezes entram em conflito com o que é imposto pela escola e tem de ser aprendido, como o professor pode agir para que os estudantes não rejeitem esses conhecimentos, não tenham dificuldades em assimilá-los ou, ainda $e$ principalmente, não dêem "respostas corretas" apenas para cumprir tarefas escolares sem sentido e inúteis?

Para os professores, esta tarefa não é fácil, porque implica uma revisão, tanto de conteúdos quanto de metodologias.

Diversos estudos têm demonstrado que as próprias crenças dos professores exercem grande influência na implementação do currículo. Por essa razão, os próprios professores devem ser investigadores em sala de aula. Entretanto, mudanças na escola são muito difíceis como práticas individuais, mas possíveis se assumidas pelo grupo de professores ao refletirem sobre sua ação (Duarte, 1996).

Para Talízina (1988), um novo conceito pode ser assimilado pelo contacto com objetos a ele relacionados. Para dirigir esse processo o professor deve organizar, desde o princípio, com seus alunos, as ações com os objetos orientadas aos aspectos que interessam. Por suas experiências, 
afirma que a ação mais adequada é a orientada para as propriedades que constituem o objeto da assimilação propriamente dita, ou seja, denominar uma característica por vez e ir identificando, no objeto, a característica indicada; quando há dúvida ou o objeto não tem a característica, já não se pode afirmar se pertence ao conceito. "Para que um conceito se forme, não como um conhecimento isolado, mas como um elemento estrutural da ciência, é muito importante introduzir os conceitos não sucessivamente, um após o outro, mas em um sistema" (p.199).

Para que as práticas pedagógicas sejam mais adequadas à formação de conceitos científicos, algumas sugestões são apontadas:

- As idéias que o aluno traz para a escola são necessárias para a construção de significados. Suas experiências culturais e familiares não podem ser negadas. Essas idéias devem ser aceitas para progressivamente evoluírem, serem substituídas ou transformadas.

- A resistência para substituir alguns conceitos só é superada se o conceito científico trouxer maior satisfação: for significativo, fizer sentido e for útil. Os conceitos científicos com maior grau de aplicabilidade, que explicam um maior número de situações e resolvem um maior número de problemas, facilitam a mudança.

- O diálogo com os alunos possibilita o diagnóstico de suas idéias em vários momentos da aprendizagem. Da mesma forma, a interação entre parceiros e a observação dos diálogos travados entre eles.

- Provocar conflito com contra-exemplos pode gerar dúvidas e insatisfação, levando os alunos a testarem suas concepções.

- Resolver problemas com um plano de atividades cognitivas deve ser estimulado, uma vez que a simples nomeação das características essenciais $e$ a repetição de definições não garantem a formação de conceito. Deve-se estimular o aluno a considerar soluções alternativas para um mesmo problema.

- Deve-se possibilitar ao aluno retomar seu processo de trabalho, explicando suas idéias e analisando a evolução das mesmas.

- No processo de formação de conceitos, é desejável desenvolver ações de inclusão -estabelecer se um objeto dado refere-se ao conceito indicado, e de dedução- reconhecer as características necessárias ou suficientes para incluir ou não os objetos em um conceito dado.

- Nem todo conceito é passível de experimentação, daí o valor de meios variados: filmes, explorações de campo etc.

- A construção de mapas conceituais (Ausubel) é um recurso valioso para o desenvolvimento conceitual.

É importante lembrar que o ensino sistemático e explícito na escola deve levar o aluno a reconceitualizações e, principalmente, desenvolver formas de pensar que se estendam para outras áreas e para situações que transcendem a sala de aula. 


\section{Referências bibliográficas}

DER VEER, R., VALSINER, J. Vygotsky: uma síntese. São Paulo: Loyola, 1996.

DUARTE, M. C. Ensino/aprendizagem da biologia: algumas reflexões suscitadas pela investigação educacional. Bol. Assoc. Port. Prof. Biol. Geol., n.6, p. 21-7, 1996.

PANOFSKY, C. et al. O desenvolvimento do discurso e dos conceitos científicos. In: Moll, L. (Org.). Vygotsky e a educação: implicações pedagógicas da psicologia. Porto Alegre: Artes Médicas, 1996. p.245-60.

PINES, L., WEST, L. Compreensão conceitual e aprendizado da ciência: uma interpretação da pesquisa dentro de um arcabouço teórico de fontes do conhecimento. s.d. (Mimeogr.).

SMITH, F. Compreendendo a leitura. 3.ed. Porto Alegre: Artes Médicas, 1991.

TALÍZINA, N. Psicologia de la enseñanza. Moscu: Progreso, 1988.

VYGOTSKY, L. Pensamento e linguagem. 3.ed. São Paulo: M. Fontes, 1991.

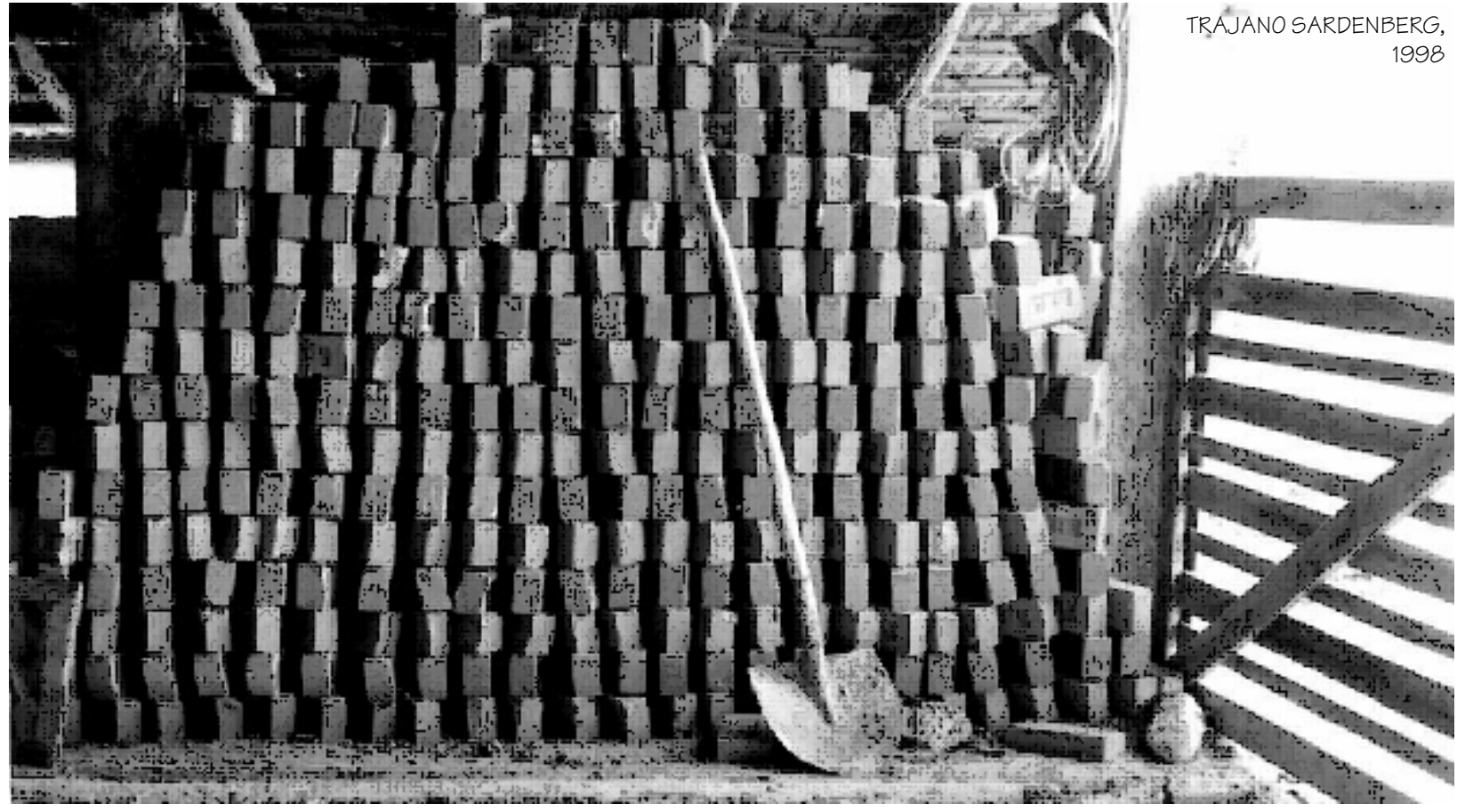

140 Interface - Comunic, Saúde, Educ 4 